Article

\title{
How Willing Are Herders to Participate in Carbon Sequestration and Mitigation? An Inner Mongolian Grassland Case
}

\author{
Yanyun Zhao ${ }^{\dagger}$, Yongzhi Yan ${ }^{\dagger}$, Qingfu Liu ${ }^{(i)}$ and Frank Yonghong $\mathrm{Li}^{*}$ \\ Ministry of Education Key Laboratory of Ecology and Resource Use of the Mongolian Plateau \& Inner Mongolia \\ Key Laboratory of Grassland Ecology, School of Ecology and Environment, Inner Mongolia University, \\ Hohhot 010021, China; 21508026@mail.imu.edu.cn (Y.Z.); 31715008@mail.imu.edu.cn (Y.Y.); \\ qingfuliu@mail.imu.edu.cn (Q.L.) \\ * Correspondence: 111981346@imu.edu.cn \\ t The authors contributed equally to the study.
}

Received: 17 May 2018; Accepted: 6 August 2018; Published: 8 August 2018

\begin{abstract}
Reasonable carbon sequestration and mitigation measures play an important role in reducing greenhouse gas emission and realizing regional sustainable development. How willing herders are to participate in carbon sequestration and mitigation directly determines the corresponding implementation effect. Relevant studies mostly focus on forest households and peasant households, but great uncertainty remains regarding herdsman households. Based on a survey of 404 herdsman households in Inner Mongolian grasslands, this study assessed the cognitive level and participation willingness of herders on carbon sequestration and mitigation of grasslands, and investigated the factors influencing their willingness to participate in the activity. We found that the cognitive level of herders on carbon sequestration and mitigation in Inner Mongolian grasslands was relatively low, with $83 \%$ of herdsman households having low cognition and $17 \%$ in the state of medium cognition. However, herders are mostly willing to take grassland carbon sequestration and mitigation measures, with $60 \%$ of herdsman households being willing to participate, $28 \%$ moderately willing to do so, and $12 \%$ of unwillingness. This pattern was mainly influenced by the impact of carbon sequestration and mitigation on household income, the economic subsidies and the call for ecological environment protection from the government. The herders tend to be willing to participate when they think that the government calls for ecological environment protection are essential. In contrast, they tend to be unwilling to participate if they think the subsidies too low and the negative effect of sequestration measure on income is essential. We found that the family financial income of herders is a key factor limiting the improvement of participation willingness in this area. It is necessary to improve the cognition of herders for the development of carbon sequestration and mitigation projects.
\end{abstract}

Keywords: carbon sequestration and mitigation; participation willingness; Inner Mongolia grassland; Logistic analysis; Decision tree model

\section{Introduction}

At present, global warming has become an indisputable fact. According to the fifth assessment report by Intergovernmental Panel on Climate Change (IPCC) [1-3], the global average surface temperature has risen $0.85^{\circ} \mathrm{C}$ from 1850 to 2012. A series of natural, social, economic, and ecological problems that are caused by global warming have become an international focus [1,2]. Human activities was considered to be a main driver. Terrestrial ecosystem has become one of the most important means for the implementation of carbon sequestration and mitigation, so as to deal with global warming $[4,5]$. Globally, many countries and government jurisdictions considered reducing emissions across natural 
terrestrial ecosystem as a part of their climate change targets, such as the Chicago Climate Exchange, which provided an good example of carbon market on private rangelands, the California that has taken efforts to make carbon sequestration and mitigation through the management and conservation of natural lands [6-8]. However, the implementation of carbon sequestration and mitigation should not only be an obligation of a nation or its government. Families were considered as a direct participant of the policy, and their cognition level and participation willingness are directly related to the implementation of relevant policies $[9,10]$. Thus, it is of the same importance to explore cognition level and participation willingness of carbon sequestration and mitigation as the policy of government.

Inner Mongolia Autonomous Region is an important animal husbandry production base in China, with the number of cattle and sheep ranking first of all the provinces in the country, and its greenhouse gas emission ranked first of four major pastoral areas [11]. However, the grassland in Inner Mongolia Autonomous proved to be a stable carbon sink, but the high carbon sequestration potential has not received much attention $[12,13]$. Since the 1980's, the land system of "double rights and one system" has been implemented in vast pastoral areas of Inner Mongolia grasslands to distribute livestock and pastures to households, making family pastures the subject of production and management [12]. As a relatively independent management unit, family pastures have independent decision-making power to grassland management. Therefore, in-depth understanding of cognition, participation willingness, and decision processes of herders on carbon sequestration and mitigation would be directly related to the implementation and popularization of carbon sequestration and mitigation measures in grassland areas, which would play an important role in realizing sustainable development of the area [14].

\section{Literature Review}

Many literatures have been reviewed to investigate participants' willingness to join environmental programs, and the participants' willingness was influenced by many factors, mainly including internal and external influencing factors [15-17]. Internal influencing factors referred to individual characteristics of the participants, such as the age of family members, their education degree, their knowledge and experience about carbon sequestration and mitigation, the number of labor force, and the financial income of the family $[14,18,19]$. For example, higher participation willingness was found in families with generally younger members than those with aging members, and in families with high financial income than those with poor financial income [20-22]. The family financial income is considered to be a key factor to participation willingness [17]. External influencing factors included government policies and call, previous participation in carbon sequestration and mitigation measures and the influence of other participants around the family. For example, participants in areas with strong government call had high participation willingness [8,15].

However, both scientific and governmental studies that are related to carbon sequestration and mitigation mostly focused on agricultural, forestry, and wetland ecosystems, while few highlighted the grassland ecosystem to date [23-25]. In this study, Baoligen and Beilike ranch in Xilinhaote City, Inner Mongolia Autonomous Region was taken as an example to evaluate the cognitive level and participation willingness of herders on grassland carbon sequestration and mitigation, and to analyze the factors that are influencing the willingness of herders on carbon sequestration and mitigation based on the survey targeting 404 herdsman households. Finally, the decision-making processes on their willingness to participate in carbon sequestration and mitigation was investigated in order to make the project more reasonable and achieving higher participation levels.

\section{Materials and Methods}

\subsection{Study Area}

The study area is located in Xilinhot City of Inner Mongolia Autonomous Region $\left(115^{\circ} 18^{\prime}-117^{\circ} 6^{\prime} \mathrm{E}\right.$; $43^{\circ} 2^{\prime}-44^{\circ} 52^{\prime} \mathrm{N}$ ) and it belongs to typical grassland of Inner Mongolia. Subjected to the influence of the middle temperate semi-arid continental climate, mean annual precipitation there is $295 \mathrm{~mm}$, and annual 
average temperature is $-0.1^{\circ} \mathrm{C}$. Minimum and maximum temperatures take form in January and July; and, they are $-22.0^{\circ} \mathrm{C}$ (January) and $18.3^{\circ} \mathrm{C}$ (July) on average, respectively. Physiognomy type is dominated by high plains and hills, and chestnut soil acts as the major soil type. In 2016, the population turns into 267,000, and among which, the Mongol forms its principal part, occupying $28 \%$. Gross regional domestic product climbs to RMB 22,814,000,000 (equivalent to about 3,347,000,000 USD), and stock farming was the leading industry. Meanwhile, per capita income of pastoral residents is RMB 22,245 [26]. Herders in the research area mainly come from three ethnic groups, the Han nationality, the Mongolian nationality, and the Hui nationality. The number of household members varies from two to six. The livestock composition of herders can be divided into three categories. The first mainly deals with large livestock, such as cattle and horses, the second is to operate small livestock mainly represented by sheep, and the third is to operate large livestock and small livestock at the same time.

\subsection{Herdsman Survey}

Based on questionnaire survey, a 24-day household investigation (June-July of 2017) was carried out in Beilike ranch (equivalent to township in terms of the administrative level) and Baoligen town (equivalent to township in terms of the administrative level). When considering that great differences lie in their demographic compositions, pasture conditions, management modes, and geographic positions, etc., a questionnaire survey for each town involving as many herders as possible and their participation rates in both towns reached $80 \%$ or above. To be specific, the number of herders taking part in this survey in Beilike ranch was 255 (information of 1 questionnaire has been lost and become invalid), that of Baoligen town was 150. In this case, the total quantity of herders achieving valid questionnaire survey was 404 (Figure 1). A survey on herders was conducted in three groups simultaneously. Each group consisted of two project participants and one local translator proficient in Mongolian and Mandarin; furthermore, while one project participant was in charge of recording, the other together with the translator took responsibilities for interviewing and investigating. Before the survey, we introduced the local carbon sequestration and mitigation policy and its impact on the household income of every herdsman household, so that herders could make objective responses. There are two main policies of grassland carbon sequestration and mitigation, the balance of livestock (feeding a certain number of livestock based on the area of grassland, beyond the range) and the policy of closure against grazing. The former subsidized $3 \mathrm{RMB}$ per $\mathrm{mu}\left(1 \mathrm{mu}=666.67 \mathrm{~m}^{2}\right.$; equivalent to about 0.44 USD), while the latter subsidized 10 RMB per mu (equivalent to about 1.47 USD). In fact, if the herder participated in the policy, they do not need to put in extra labor. The two policies both aim to control and reduce the number of livestock, having a negative impact on household financial income.

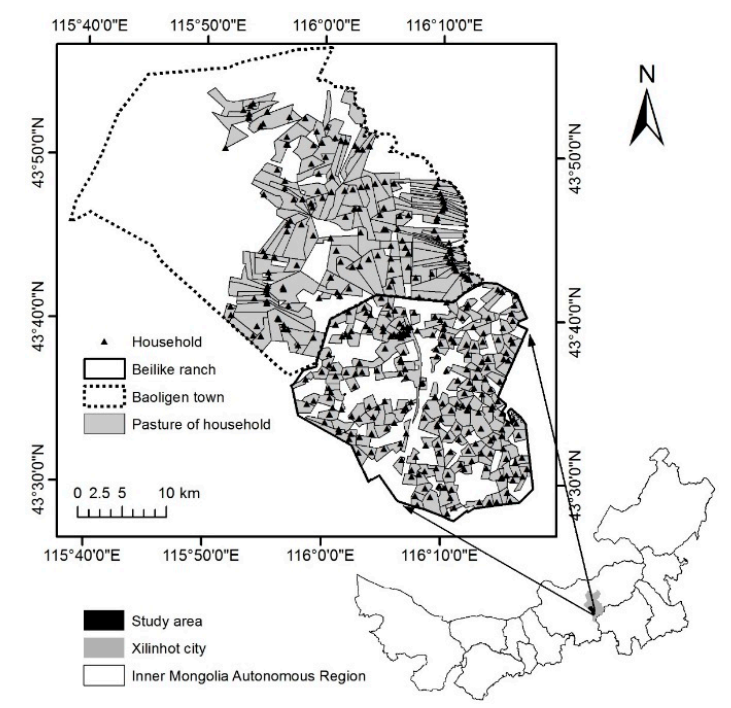

Figure 1. Distribution of surveyed herdsman households. 


\subsection{Data Analysis}

\subsubsection{Evaluation of Herders' Cognition on Grassland Carbon Sequestration and Mitigation}

Based on the survey data, herders' cognition on grassland carbon sequestration and mitigation was quantified by using a common evaluation standard of herders' answers about carbon sequestration and mitigation in grassland areas. There were four questions aiming at the theme of "grassland carbon sequestration and mitigation" (Table 1).

Table 1. Question setting and evaluation standards of herdsman households' cognition on grassland carbon sequestration and mitigation.

\begin{tabular}{lc}
\hline \multicolumn{1}{c}{ Question } & Evaluation Standard \\
\hline $\begin{array}{l}\text { Do you know that temperature rise is mainly a result of the increase in carbon } \\
\text { dioxide concentration? }\end{array}$ & Low Medium High \\
\hline Do you know that grasslands can absorb carbon dioxide? & \\
\hline Do you know that carbon can be sold for money (carbon trading)? & \\
\hline Do you understand carbon sequestration and mitigation policies? & \\
\hline
\end{tabular}

3.3.2. Analysis on the Willingness of Herdsman Households to Participate in Grassland Carbon Sequestration and Mitigation and the Corresponding Influencing Factors

Survey results of the participation willingness of herdsman households on carbon sequestration and mitigation were divided into willing, neutral, and unwilling types, and then the overall situation of participation willingness on carbon sequestration and mitigation in the area was collected. As an independent decision-making subject of grassland management, family pastures would make its own decisions based on the costs and benefits of carbon sequestration and mitigation measures. Therefore, influencing factors of herdsman households' willingness to participate in carbon sequestration and mitigation were divided into costs, benefits, and other external factors (Table 2). Cost influencing variables included economic costs, workforce costs, and skill costs of carbon sequestration and mitigation measures. Benefits influencing variables included internal benefits and external benefits. External benefits referred to the impact of carbon sequestration and mitigation measures on family income and the restoration of grassland ecological environment. Other external influencing factors included the cognitive level of herdsman households on grassland carbon sink as well as carbon sequestration and mitigation, and the adoption of carbon sequestration and mitigation measures by surroundings. In order to further analyze the influencing factors and mechanisms on their participation willingness, the influence of uncertain factors of herdsman willingness was excluded, and herdsman households (286 in total) whose participation willingness was divided into willing and unwilling were selected to establish a binary logistic regression model to analyze the main influencing factors. A decision tree was used to analyze and explore characteristics of their willingness to participate in the project in this area along with their participation process. Logistic regression analysis was performed via SPSS 20.0. The decision tree analysis was carried out by using the "ctree" function of the "party" package of $\mathrm{R}$ language.

Table 2. Meaning and value range of variables in the binary logistic regression model.

\begin{tabular}{clll}
\hline Variable Type & Variable Subtype & \multicolumn{1}{c}{ Variable Name } & Variable Meaning \\
\hline & & The willingness to adopt carbon & \\
Response variable & sequestration and mitigation & $0=$ willing \\
& measures under the existing & $1=$ unwilling \\
& conditions $(Y)$ & \\
\hline
\end{tabular}


Table 2. Cont.

\begin{tabular}{|c|c|c|c|}
\hline Variable Type & Variable Subtype & Variable Name & Variable Meaning \\
\hline \multirow{8}{*}{ Influencing variable } & \multirow{3}{*}{ Benefit factor } & $\begin{array}{l}\text { The impact of adopting carbon } \\
\text { sequestration and mitigation measures } \\
\text { on family income (X1) }\end{array}$ & $\begin{array}{l}\text { very important }=1 \\
\text { moderately important }=2 \\
\text { not important }=3\end{array}$ \\
\hline & & $\begin{array}{l}\text { The effect on grassland ecological } \\
\text { protection }(\mathrm{X} 2)\end{array}$ & $\begin{array}{l}\text { very important }=1 \\
\text { moderately important }=2 \\
\text { not important }=3\end{array}$ \\
\hline & & $\begin{array}{l}\text { The response to the government call for } \\
\text { ecological environment protection (X3) }\end{array}$ & $\begin{array}{l}\text { very important }=1 \\
\text { moderately important }=2 \\
\text { not important }=3\end{array}$ \\
\hline & \multirow{3}{*}{ Cost factor } & $\begin{array}{l}\text { The importance of providing economic } \\
\text { subsidies by the government }(X 4)\end{array}$ & $\begin{array}{l}\text { very important }=1 \\
\text { moderately important }=2 \\
\text { not important }=3\end{array}$ \\
\hline & & $\begin{array}{l}\text { Corresponding trainings and guidance } \\
\text { on taking carbon sequestration and } \\
\text { mitigation measures (X5) }\end{array}$ & $\begin{array}{l}\text { very important }=1 \\
\text { moderately important }=2 \\
\text { not important }=3\end{array}$ \\
\hline & & $\begin{array}{l}\text { The number of family members } \\
\text { engaged in pasturing occupations (X6) }\end{array}$ & specific number \\
\hline & \multirow{2}{*}{ Other factors } & $\begin{array}{l}\text { The cognitive level of carbon sink and } \\
\text { carbon sequestration and mitigation on } \\
\text { grasslands (X7) }\end{array}$ & $\begin{array}{l}\text { The numbers of } \\
\text { "Low" question }\end{array}$ \\
\hline & & $\begin{array}{l}\text { The adoption of carbon sequestration } \\
\text { and mitigation measures by the } \\
\text { surrounding people (X8) }\end{array}$ & $\begin{array}{l}\text { very important }=1 \\
\text { moderately important }=2 \\
\text { not important }=3\end{array}$ \\
\hline
\end{tabular}

\section{Results}

\subsection{Cognition on Grassland Carbon Sequestration and Mitigation by Herdsman Households}

In this study, four questions were set up about herders' cognition on carbon sequestration and mitigation (Table 1). Generally speaking, the herders had very low cognition in view of grassland carbon sequestration and mitigation in research area, $83 \%$ of the herders were in the state of low cognition, and only 17\% were in the state of medium cognition (Figure 2).

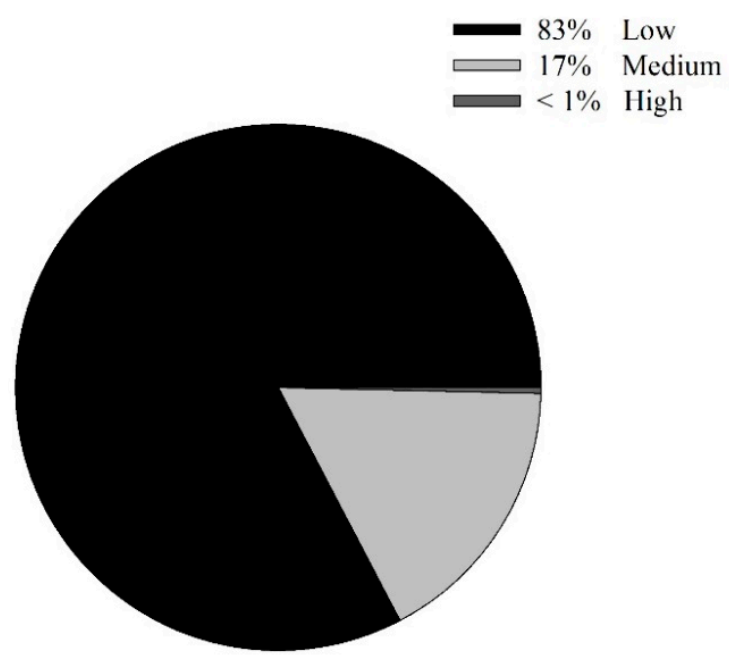

Figure 2. Proportion of cognition levels of herdsman households on grassland carbon sequestration and mitigation. 
4.2. Herders' Willing to Participate in Grassland Carbon Sequestration and Mitigation and the Corresponding Influencing Factors

The statistical analysis on the willingness of 404 herdsman households to participate in grassland carbon sequestration and mitigation showed that $60 \%$ were willing to adopt relevant measures, $28 \%$ held a neutral attitude, and $12 \%$ were unwilling to be part of it (Figure 3). A logistic regression analysis was carried out after herdsman households with neutral willingness were excluded (118 in total). First, the multicollinearity diagnosis was performed on eight explanatory variables, results of which showed that variance inflation factors of the selected eight explanatory variables were all smaller than 10, indicating no significant multicollinearity between the explanatory variables. The overall effect of the model was significant $(p<0.01)$, indicating a good fitting effect on the data. Among the eight explanatory variables, the three explanatory variables, including "the impact on family income", "the government call for ecological environment protection", and "the importance of providing economic subsidies by the government", suggested the highest explanatory rate for the willingness of herdsman households to participate in carbon sequestration and mitigation, with the regression coefficients being $-1.262,1.01$, and -1.219 , respectively (Table 3 ).

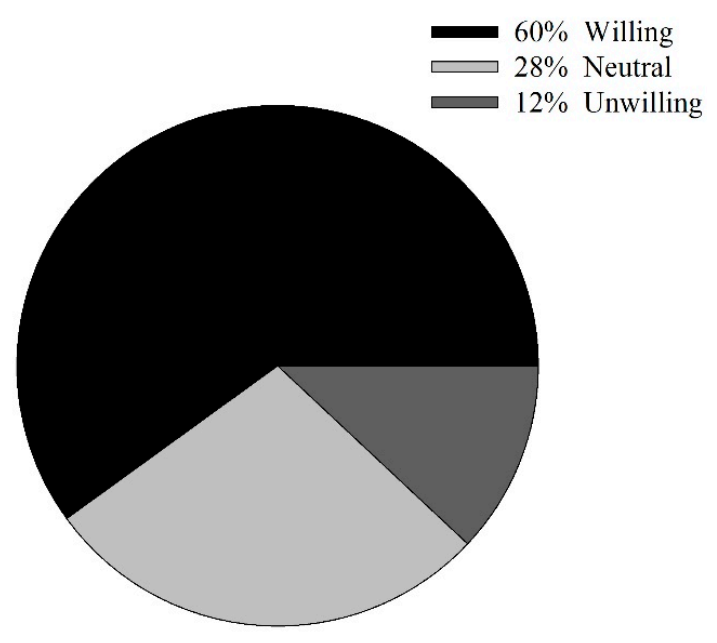

Figure 3. Proportion of the willingness of herdsman households to participate in grassland carbon sequestration and mitigation.

Table 3. Estimation results of the willingness of herdsman households to participate in carbon sequestration and mitigation based on the logistic regression model.

\begin{tabular}{lcrr}
\hline \multicolumn{1}{c}{ Explanatory Variable } & Regression Coefficient & Standard Error & $p$ \\
\hline The importance of the impact on family income & $-1.262^{* *}$ & 0.441 & 0.005 \\
\hline The protection effect on grassland ecological environment & 0.557 & 0.326 & 0.094 \\
\hline $\begin{array}{l}\text { The response to the government call for ecological environment } \\
\text { protection }\end{array}$ & $1.01 * *$ & 0.332 & 0.003 \\
\hline The importance of providing economic subsidies by the government & $-1.219^{* *}$ & 0.322 & 0.000 \\
\hline $\begin{array}{l}\text { The corresponding trainings and guidance for carbon sequestration } \\
\text { and mitigation measures }\end{array}$ & 0.357 & 0.331 & 0.298 \\
\hline $\begin{array}{l}\text { The number of family members engaged in pasturing occupations } \\
\text { The cognitive level of carbon sink and carbon sequestration and } \\
\text { mitigation in grassland }\end{array}$ & 0.094 & 0.344 & 0.604 \\
\hline $\begin{array}{l}\text { The adoption of carbon sequestration and mitigation measures by the } \\
\text { surrounding people }\end{array}$ & -0.211 & 0.399 & 0.18 \\
\hline Constant & -0.27 & 0.208 & 0.224 \\
\hline
\end{tabular}

** indicated the significance of $1 \%$. 


\subsection{The Decision-Making Process of Herdsman Households to Participate in Carbon Sequestration and Mitigation}

In order to further explore the decision-making process of herdsman households to participate in carbon sequestration and mitigation in the research area, a conditional inference decision tree was established by selecting three explanatory variables with significant influence on the willingness of herdsman households to participate in logistic regression analysis (Figure 4). The results suggested that when herdsman households made decisions to do so, they would follow four decision-making processes as shows with the result of willing or not. Every split in this decision tree is based on the three significant explanatory variables above. Through the decision tree, 286 herders were classified into four groups. The first group has 142 herders, $90.8 \%$ of them are willing to participate, and $9.2 \%$ are not willing. The second group has 76 herders, $85.5 \%$ of them are willing, and $14.5 \%$ are not willing. The third group has 37 herders, $51.4 \%$ of them are willing, and $14.5 \%$ are not willing. The fourth group has 31 herders, $87.1 \%$ are willing, and $12.9 \%$ are not willing. The feature of herders that are unwilling to participate is considering the negative effect of carbon sequestration and mitigation measures to be very important. The financial income of herders is a key factor that is limiting the improvement of participation willingness in this area.

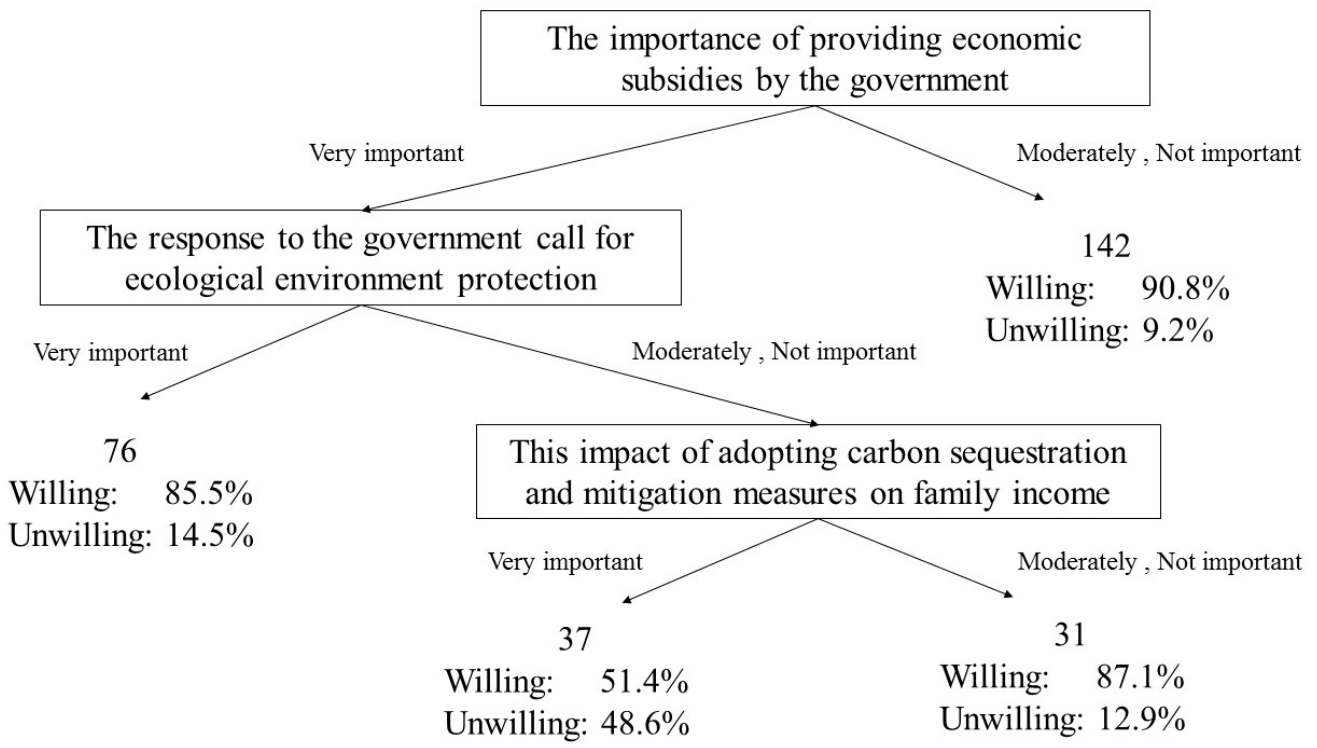

Figure 4. Decision tree for the participation willingness of herdsman households.

\section{Discussion}

Unlike some studies in other areas, such as forest, farmland, and wetland, the results of this study showed that $83 \%$ of the 404 herdsman households that were surveyed in this area were in the state of no understanding for grassland carbon sequestration and mitigation, and only $17 \%$ were in the state of understanding, implying a considerably lower cognitive level [6,21,22]. Hong found that peasant households who had previously participated in carbon sink projects had a significantly improved cognition level than those that did not participate in these projects [23]. Therefore, the lower cognitive level by herdsman households in grassland pastoral areas than those in forest areas may be resulted from the stronger carbon sequestration capacity of the forest ecosystem than that of the grassland ecosystem, prior attention paid to carbon sequestration and mitigation in the forest and other areas, and earlier implementation of carbon sequestration and mitigation measures in these areas, which is making carbon sequestration and mitigation related knowledge more popular. As the essential economic activity subjects and the most basic decision-making units in pastoral areas, herders have become the most important and direct influencing factors for ecological environment 
changes in pastoral areas by utilizing grassland resources and economic management behaviors. Moreover, their cognitive level on grassland carbon sequestration and mitigation would influence the promotion and implementation of the corresponding measures there, as well as the subsequent sustainable development $[8,14,27]$. However, this study shows the herders' cognitive level, and the protection effect of carbon sequestration mitigation on grassland has no significant influence on herders' willingness to participate. This may be mainly due to the fact there are a large number of herders ( $83 \%$ of 404 ) with low cognition in the research area. Unlike Zhu et al. [22] but similar to Kong et al. [21], we find that the number of family members and the corresponding trainings and guidance have no significant effect on herders' willingness to participate. This finding may be explained by the fact that local carbon sequestration and mitigation policies are easy to be adopted. Adopting these measures does not require much labor or related trainings and guidance.

It is interesting to note that herders have relatively strong willingness to participate in carbon sequestration and mitigation measures in this area (willing, 60\%; neutral, 28\%; and, not willing, 12\%) when compared with other regions in China and other countries, and the government call has a relatively strong impact on herders willingness $[17,23]$. This finding may be attributed to the long tradition culture of Mongolian plateau and the trust of herders to government [17]. Since the ancient times, the Mongolian people living in the vast land of the Mongolian plateau have gradually formed a set of habits and customs that are based on the harmonious coexistence between man and nature and the sustainable use of natural resources. On this basis, they have formulated the ancient customary law and written customary law of the han state of Mongolia to the present day, in order to protect the grassland resources and water resources [28]. In addition, the government calls for ecological environment protection, such as carbon sequestration and mitigation, to respond to the impact of global warming and the promotion of the construction of ecological civilization. Therefore, herders and the government agree on the issue of protecting grassland. Meanwhile, this result indicates that herders have a high cognition of the local sustainability problems but little of the knowledge of the international carbon trading. Thus, the low cognition may restrict the future establishment of carbon market in this area, which is considered to be an effective way of carbon sequestration and mitigation $[8,29]$. On the other hand, although herders have a relatively strong willingness to participate in carbon sequestration and mitigation measures in this area, there is also one group with relative high unwillingness to participation based on the conditional inference decision tree analysis. Similar to many previous studies, the family income plays a key role in improving herders' willingness $[15,17,22,24]$. This suggests that it is important to protect the herders' family income for improving their willingness.

This study has some limitations because it was conducted in a relative small temporal and spatial scale. Future studies should consider a longer temporal scale and a larger spatial scale to make a comprehensive analysis of herders' willingness to participate in the project. In general, in order to effectively improve the willingness to participate, it is important to protect the family income of herders. However, the two policies of carbon sequestration and mitigation in this area both aim to control and reduce the number of livestock, which would cause potential economic loss. It is necessary to implement other practices, such as inter-sowing grass and legumes, fertilization, and introducing earthworms [30]. It is important to improve the herders' cognition of carbon market and international carbon trading for the future establishment and operation of carbon market, even though the cognitive level has no significant influence on willingness to participate in this study.

\section{Conclusions}

This study assessed the carbon sequestration and mitigation participation willingness of herders and its influencing factors in Inner Mongolian grassland. The result indicated that herders have high participation willingness but low cognition of carbon sequestration and mitigation in this area. The family income is the key influence factor. Therefore, protection of herders' family income should be taken into full consideration in carbon sequestration. Considering the local current measures and 
its potential consequence of economic loss, it may be better to consider some other measures such as inter-snowing grasses and legumes, fertilization, irrigation and so on. In addition, in consideration of future establishment of carbon market it is necessary to strength the cognition of herders, even the cognition level has no significant influence on willingness to participate in this area.

Author Contributions: Y.Z., Y.Y., Q.L. conducted the herdsman survey. Y.Z. and Y.Y. analyzed the data. Y.Z., Y.Y., Q.L. contributed to drafting the paper. F.Y.L. contributed to the design of the paper. F.Y.L. were in charge of the final version of the paper.

Funding: This research was funded by The National Key Technology Support Program grant number 2015BAC02B04, Inner Mongolia Science \& Technology Plan grant number 201601061, and The National Basic Research Program of China grant number 31760150. The APC was funded by the National Basic Research Program of China grant number 31760150.

Acknowledgments: We are grateful to Rihui Cong, Siqi Liu and Ling Zhu for the field work. We also appreciate Gang Feng for improving the English writing.

Conflicts of Interest: The authors declare no conflicts of interest.

\section{References}

1. Sapkota, T.B.; Shankar, V.; Rai, M.; Jat, M.L.; Stirling, C.M.; Singh, L.K.; Jat, H.S.; Grewal, M.S. Reducing global warming potential through sustainable intensification of basmati rice-wheat systems in India. Sustainability 2017, 9, 1044. [CrossRef]

2. Kosaka, Y.; Xie, S.-P. Recent global-warming hiatus tied to equatorial pacific surface cooling. Nature 2013, 501, 403-407. [CrossRef] [PubMed]

3. IPCC. The Physical Science Basis. Contribution of Working Group I to the Fifth Assessment Report; Intergovernmental Panel on Climate Change: Geneva, Switzerland, 2013.

4. Abonyi, A.; Acs, E.; Hidas, A.; Grigorszky, I.; Varbiro, G.; Borics, G.; Kiss, K.T. Functional diversity of phytoplankton highlights long-term gradual regime shift in the middle section of the danube river due to global warming, human impacts and oligotrophication. Freshw. Biol. 2018, 63, 456-472. [CrossRef]

5. Cook, J.; Oreskes, N.; Doran, P.T.; Anderegg, W.R.L.; Verheggen, B.; Maibach, E.W.; Carlton, J.S.; Lewandowsky, S.; Skuce, A.G.; Green, S.A.; et al. Consensus on consensus: A synthesis of consensus estimates on human-caused global warming. Environ. Res. Lett. 2016, 11, 4. [CrossRef]

6. Cameron, D.R.; Marvin, D.C.; Remucal, J.M.; Passero, M.C. Ecosystem management and land conservation can substantially contribute to California's climate mitigation goals. Proc. Natl. Acad. Sci. USA 2017, 114, 12833-12838. [CrossRef] [PubMed]

7. Hudiburg, T.; Law, B.; Turner, D.P.; Campbell, J.; Donato, D.C.; Duane, M. Carbon dynamics of oregon and northern california forests and potential land-based carbon storage. Ecol. Appl. 2009, 19, 163-180. [CrossRef] [PubMed]

8. Cook, S.L.; Ma, Z. The interconnectedness between landowner knowledge, value, belief, attitude, and willingness to act: Policy implications for carbon sequestration on private rangelands. J. Environ. Manag. 2014, 134, 90-99. [CrossRef] [PubMed]

9. Brogaard, S.; Zhao, X.Y. Rural reforms and changes in land management and attitudes: A case study from Inner Mongolia, China. Ambio 2002, 31, 219-225. [CrossRef] [PubMed]

10. Junquera, B.; Del Brio, J.A.; Muniz, M. Citizens' attitude to reuse of municipal solid waste: A practical application. Resour. Conserv. Recycl. 2001, 33, 51-60. [CrossRef]

11. Chen, Y.; Shang, J. Estimation and effecting factor decomposition of green house gas emission of animal husbandry industry in four pastoral areas. China Popul. Resour. Environ. 2014, 24, 89-95. (In Chinese)

12. Zhang, Q.; Ding, Y.; Ma, W.; Kang, S.; Li, X.; Niu, J.; Hou, X.; Li, X.; Sarula. Grazing primarily drives the relative abundance change of $\mathrm{C}-4$ plants in the typical steppe grasslands across households at a regional scale. Rangel. J. 2014, 36, 565-572.

13. Wu, X.; Kang, X.M.; Liu, W.J.; Cui, X.Y.; Hao, Y.B.; Wang, Y.F. Using the dndc model to simulate the potential of carbon budget in the meadow and desert steppes in Inner Mongolia, China. J. Soils Sediments 2018, 18, 63-75. [CrossRef]

14. Ma, S.; Swinton, S.M.; Lupi, F.; Jolejole-Foreman, C. Farmers' willingness to participate in payment-forenvironmental-services programmes. J. Agric. Econ. 2012, 63, 604-626. [CrossRef] 
15. Soderqvist, T. Are farmers prosocial? Determinants of the willingness to participate in a Swedish catchment-based wetland creation programme. Ecol. Econ. 2003, 47, 105-120. [CrossRef]

16. Defrancesco, E.; Gatto, P.; Runge, F.; Trestini, S. Factors affecting farmers' participation in agri-environmental measures: A northern Italian perspective. J. Agric. Econ. 2008, 59, 114-131. [CrossRef]

17. Lastra-Bravo, X.B.; Hubbard, C.; Garrod, G.; Tolon-Becerra, A. What drives farmers' participation in eu agri-environmental schemes? Results from a qualitative meta-analysis. Environ. Sci. Policy 2015, 54, 1-9. [CrossRef]

18. Li, Q.; Long, R.; Chen, H. Empirical study of the willingness of consumers to purchase low-carbon products by considering carbon labels: A case study. J. Clean. Product. 2017, 161, 1237-1250. [CrossRef]

19. Khanal, P.N.; Grebner, D.L.; Munn, I.A.; Grado, S.C.; Grala, R.K.; Henderson, J.E. Evaluating non-industrial private forest landowner willingness to manage for forest carbon sequestration in the Southern United States. For. Policy Econ. 2017, 75, 112-119. [CrossRef]

20. Mostafa, M.M. Egyptian consumers' willingness to pay for carbon-labeled products: A contingent valuation analysis of socio-economic factors. J. Clean. Product. 2016, 135, 821-828. [CrossRef]

21. Kong, F.; Xiong, K.; Zhang, N. Determinants of farmers' willingness to pay and its level for ecological compensation of Poyang lake wetland, china: A household-level survey. Sustainability 2014, 6, 6714-6728. [CrossRef]

22. Zhu, H.; Guan, Z.; Wei, X. Factors influencing farmers' willingness to participate in wetland restoration: Evidence from china. Sustainability 2016, 8, 1325. [CrossRef]

23. Hong, M.; Hu, C.; Gu, L.; Zhang, X.; Bao, J. Households' willingness in participating forest management of carbon sequestration trading and the related influencing factors under the Redd+. J. Zhejiang Agric. For. Univ. 2017, 34, 207-214. (In Chinese)

24. Tolunay, A.; Bassullu, C. Willingness to pay for carbon sequestration and co-benefits of forests in Turkey. Sustainability 2015, 7, 3311-3337. [CrossRef]

25. Lal, R.; Follett, F.; Stewart, B.A.; Kimble, J.M. Soil carbon sequestration to mitigate climate change and advance food security. Soil Sci. 2007, 172, 943-956. [CrossRef]

26. Xilinhot Bureau of Statistics. Statistical Yearbook of Xilinhot City; Xilinhot Bureau of Statistics: Xilinhot, China, 2016.

27. Vanslembrouck, I.; Van Huylenbroeck, G.; Verbeke, W. Determinants of the willingness of Belgian farmers to participate in agri-environmental measures. J. Agric. Econ. 2002, 53, 489-511. [CrossRef]

28. Zhang, M.A.; Borjigin, E.; Zhang, H. Mongolian nomadic culture and ecological culture: On the ecological reconstruction in the agro-pastoral mosaic zone in northern china. Ecol. Econ. 2007, 62, 19-26. [CrossRef]

29. Ritten, J.P.; Bastian, C.T.; Rashford, B.S. Profitability of carbon sequestration in western rangelands of the United States. Rangel. Ecol. Manag. 2012, 65, 340-350. [CrossRef]

30. Conant, R.T.; Paustian, K.; Elliott, E.T. Grassland management and conversion into grassland: Effects on soil carbon. Ecol. Appl. 2001, 11, 343-355. [CrossRef] 